\title{
Consequences of radiopharmaceutical extravasation and therapeutic interventions: a systematic review
}

\author{
Jochem van der Pol $^{1}$ • Stefan Vöö ${ }^{1}$ - Jan Bucerius ${ }^{1,2}$ • Felix M. Mottaghy ${ }^{1,2}$
}

Received: 13 January 2017 / Accepted: 7 March 2017 / Published online: 16 March 2017

(C) The Author(s) 2017. This article is published with open access at Springerlink.com

\begin{abstract}
Purpose Radiopharmaceutical extravasation can potentially lead to severe soft tissue damage, but little is known about incidence, medical consequences, possible interventions, and effectiveness of these. The aims of this study are to estimate the incidence of extravasation of diagnostic and therapeutic radiopharmaceuticals, to evaluate medical consequences, and to evaluate medical treatment applied subsequently to those incidents.

Methods A sensitive and elaborate literature search was performed in Embase and PubMed using the keywords "misadministration", "extravasation", "paravascular infiltration", combined with "tracer", "radionuclide", "radiopharmaceutical", and a list of keywords referring to clinically used tracers (i.e. "Technetium-99m", "Yttrium-90"). Reported data on radiopharmaceutical extravasation and applied interventions was extracted and summarised.

Results Thirty-seven publications reported 3016 cases of diagnostic radiopharmaceutical extravasation, of which three cases reported symptoms after extravasation. Eight publications reported 10 cases of therapeutic tracer extravasation. The most severe symptom was ulceration. Thirty-four different intervention and prevention strategies were performed or proposed in literature.

Conclusions Extravasation of diagnostic radiopharmaceuticals is common. ${ }^{99 \mathrm{~m}} \mathrm{Tc},{ }^{123} \mathrm{I},{ }^{18} \mathrm{~F}$, and ${ }^{68} \mathrm{Ga}$ labelled tracers
\end{abstract}

Felix M. Mottaghy

fmottaghy@ukaachen.de

1 Department of Radiology and Nuclear Medicine, Maastricht University Medical Centre (MUMC+), Postbox 5800, 6202 AZ Maastricht, The Netherlands

2 Department of Nuclear Medicine, University Hospital, RWTH Aachen University, Pauwelsstr. 31, 52072 Aachen, Germany do not require specific intervention. Extravasation of therapeutic radiopharmaceuticals can give severe soft tissue lesions. Although not evidence based, surgical intervention should be considered. Furthermore, dispersive intervention, dosimetry and follow up is advised. Pharmaceutical intervention has no place yet in the immediate care of radiopharmaceutical extravasation.

Keywords Extravasation · Dose infiltration . Radiopharmaceuticals $\cdot$ Radiation ulcer

\section{Introduction}

High doses of radiation exposure can potentially cause severe tissue damage, such as skin desquamation and necrosis. Extravasation of radionuclides used in nuclear medicine practice results in localized tissue retention of the radiopharmaceutical and subsequently in an unintended extended local radiation exposure. Because of the character of the radiation, extravasation of therapeutic radiopharmaceuticals has the highest tendency to result in tissue damage, although some cases of tissue damage following the extravasation of diagnostic radiopharmaceuticals have been reported [1].

Knowledge of possible consequences and interventions to prevent tissue damage are vital for an adequate risk-adapted management after extravasation of radiopharmaceuticals. The EANM procedure guideline for 90Y-radiolabeled ibritumomab tiuxetan (Zevalin $\left.{ }^{\circledR}\right)$ is the only guideline that gives limited practical advice in case of extravasation, advising local hyperthermia, elevation of the extremity and gentle massage [2]. The SNMMI procedure standard for palliative treatment for painful bone metastases advises local heat to promote reabsorption [3]. Other EANM and SNMMI guidelines covering radionuclide 
therapy do not give any practical information in case of extravasation, regardless of the potential complications [4-7].

To our knowledge, no previous study or literature review has been performed to summarize the effects of the extravasation of commonly applied diagnostic or therapeutic radiopharmaceuticals. Knowledge of the incidence of extravasation, the severity of these effects, and about the effectivity of interventions is necessary for adequate clinical response in case of extravasation, as well as in development of guidelines covering radiopharmaceutical extravasation. The purpose of this study was, therefore, to review systematically previously published data on the incidence and clinical outcome of radioactive extravasations and to summarize the reported incidences of events of most of the clinically used radiopharmaceuticals, the applied interventions, as well as the reported clinical outcomes.

\section{Materials and methods}

\section{Search strategy}

A computer-aided search of the PubMed/MEDLINE and Embase databases was conducted to find relevant published articles on extravasation of radiopharmaceuticals. No start date limit was used. No language limitation was applied in the initial search strategy. The search string was composed of several synonymous keywords for extravasation combined as a group using the "AND" operator with a combination of the keywords "radiopharmaceutical" and an extensive list of clinically used isotopes in five different notations (i.e. "I-131", "I131", "131I”, "Iodine 131", "131 iodine"). In PubMed, all keywords were combined with a MESH equivalent when available, as well as an equivalent with the "Pharmaceutical action" tag. The used search strings are shown in Table 1. The search was updated until November 2016.

Studies reporting radiopharmaceutical extravasation in humans were eligible for inclusion. Only studies written in the languages mastered by the authors were included: English, Spanish, French, Italian, German, Hungarian, Romanian, or Dutch. No other limits were imposed. Animal studies were excluded.

Two reviewers (J.P. and S.V.) independently reviewed titles and abstracts to find articles reporting cases of extravasation, or to find literature otherwise relevant to the subject. In case of disagreement on relevance, the full text was retrieved. To expand our search, bibliographies of articles that finally remained after the selection process were screened for potentially relevant references. Subsequently, the corresponding full text articles were retrieved for further reading and selection.

\section{Data extraction}

The following data were extracted whenever available from eligible studies: first author, journal and year of publication, population studied, number of reported extravasations, radiopharmaceutical, injection place, estimated administered volume, estimated extravasated activity and tissue dose, description of tissue damage and delay since injection, duration of follow-up, and applied medical interventions.

\section{Data analysis}

Reported incidents were categorized and pooled according to radiopharmaceutical that was administered. Ratios were calculated between the pooled reported incidence of extravasation versus the number of reported incidences of adverse soft tissue effects. Cases were grouped and displayed in tables sorted by radiopharmaceutical separately for diagnostic and therapeutic radiopharmaceuticals. Furthermore, literature references that described interventions were organised in three categories: 1) advised by reference, 2) applied in case report, and 3) discouraged by reference.

Table 1 Search strings applied in PubMed/MEDLINE and Embase with search results specified to search engine and search strings

\begin{tabular}{|c|c|c|c|}
\hline No. & Search strings ${ }^{\mathrm{a}}$ & Pubmed/MEDLINE & Embase \\
\hline 1 & $\begin{array}{l}\text { "Extravasation of Diagnostic and Therapeutic Materials" [Mesh] OR "Extravasation of Diagnostic } \\
\text { and Therapeutic Materials" OR "extravasation" OR "infiltration" OR "misadministration" }\end{array}$ & 110.807 & 171.853 \\
\hline 2 & 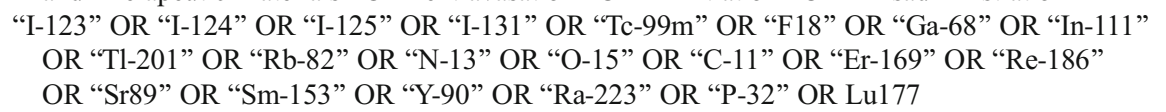 & 213.922 & 361.049 \\
\hline 3 & $\begin{array}{l}\text { "Radiopharmaceuticals"[Mesh] OR "Radiopharmaceuticals" OR "Radioisotopes”[Mesh] OR } \\
\text { "Radioisotopes" }\end{array}$ & 301.588 & 15.949 \\
\hline 4 & $1 \operatorname{AND}(2 \mathrm{OR} 3)$ & 2.153 & 3.493 \\
\hline
\end{tabular}

Search strategy with number of yielded results in PubMed/MEDLINE and Embase.

The "Mesh" tag was omitted for the Embase search strings

a In the actual search strings used, all radionuclides were spelled using five different conventions, i.e. the keyword "I-123" was accompanied by "I123",

"123I", "Iodine 123", and "123 Iodine", grouped together with the "OR" operand 


\section{Results}

The searches performed using Pubmed and Embase resulted in 2153 and 3493 publications respectively (Table 1). Of these, 1123 search results were found using both search engines yielding a total of 4523 abstracts after subtraction. Rejected abstracts described irrelevant animal studies (1012), reported extravasation of other agents than radionuclides (198), mentioned infiltration of other nature than infiltration of radiopharmaceuticals (2424), described lymph drainage studies or other nuclear medicine studies in which extravasation is a pathological finding, i.e. urinary extravasation in ${ }^{99 \mathrm{~m}} \mathrm{Tc}$-mercaptoacetyltriglycine (MAG3) (196), or publications about radionuclide use for other purposes than nuclear medicine studies (603), such as radioimmunoassays. The full text was retrieved for the remaining 81 publications. The references of relevant publications were screened, of which the full text was retrieved. In total, 108 full text articles or conference abstracts were retrieved for further evaluation. Radiopharmaceutical extravasation was reported in 44 publications, of which 37 about diagnostic and eight about therapeutic radiopharmaceuticals. Another 10 publications contained information on extravasation based on expert opinion or cited work.

Cases of diagnostic extravasation are summarised in Table 2. In total, 37 publications reported 3016 cases of radiopharmaceutical extravasation. For three cases symptoms and follow up was reported $(0,1 \%)$ [42-44]. When grouped together, a total of 3003 cases described extravasation without reported symptoms after extravasation of 18F-fluorodeoxyglucose (FDG) (332) and 99mTc-labelled tracers (2671) [8-41]. Radiation ulcers in two patients following extravasation of 201Tl-thallous chloride were the most severe injuries reported [43, 44]. In one case a radiation ulcus was diagnosed 2 years. The injected activity and estimated tissue dose were $74 \mathrm{MBq}$ and $200 \mathrm{~Gy}$, respectively [43]. In the second case the diagnosis radiation ulcus was made after 3 years. The injected activity was $111 \mathrm{MBq}$ and the worst case estimate of tissue dose was 250 Gy [44]. A pruritic and erythematous patch was described following the extravasation of $34 \mathrm{MBq}$ of 131I-iodocholesterol, with a worst case tissue dose estimate of 490 Gy [42]. Other reported cases of diagnostic extravasation cases did not describe dosimetric parameters or follow-up.

Eight publications reported a total of 10 cases of therapeutic radiopharmaceutical extravasation [46-53]. Radionecrosis was the most severe symptom reported in five cases [47, 49, 50], although three cases reported needle track necrosis that resolved spontaneously [47]. The results and references are summarised in Table 3. Table 4 summarises a total of 34 interventions that are advised or, contrarily, discouraged in literature and those which are applied in reported cases.

\section{Discussion}

Multiple retrospective case series on bone scintigraphy, as well as $18 \mathrm{~F}-\mathrm{FDG}$ positron emission tomography (PET) report a large proportion of at least partial tracer extravasation [18-31]. Although there was no clinical follow-up after extravasation reported in these publications, no adverse reactions have

Table 2 Summary of reported cases of diagnostic radiopharmaceutical extravasation

\begin{tabular}{|c|c|c|c|c|c|}
\hline References & $\begin{array}{l}\text { Total reported } \\
\text { cases }\end{array}$ & Radiopharmaceutical & $\begin{array}{l}\text { No. of patients } \\
\text { with reported } \\
\text { radiation injury }\end{array}$ & $\begin{array}{l}\text { No. of patients } \\
\text { with reported } \\
\text { follow-up }\end{array}$ & $\begin{array}{l}\text { Most severe } \\
\text { injury reported }\end{array}$ \\
\hline [8-17] & 332 & 18F-FDG & 0 & 0 & \\
\hline$[18-31]$ & 2584 & ${ }^{99 \mathrm{~m}} \mathrm{Tc}$ bone tracers & 0 & 0 & \\
\hline [32] & 3 & ${ }^{99 \mathrm{~m}}$ Tc-MAA & 0 & 0 & \\
\hline [33] & 1 & ${ }^{99 m}$ Tc-DMSA & 0 & 0 & \\
\hline$[34,35]$ & 10 & ${ }^{99 m}$ Tc-DTPA & 0 & 0 & \\
\hline [36] & 1 & ${ }^{99 \mathrm{~m}} \mathrm{Tc}-\mathrm{HMPAO}$ & 0 & 0 & \\
\hline [37] & 1 & ${ }^{99 m}$ Tc-MAG3 & 0 & 0 & \\
\hline$[19,38,39]$ & 15 & ${ }^{99 \mathrm{~m}} \mathrm{Tc}$-pertechnetate & 0 & 0 & \\
\hline$[40,41]$ & 2 & ${ }^{99 \mathrm{~m}} \mathrm{Tc}$-sestamibi & 0 & 0 & \\
\hline [19] & 38 & ${ }^{99 \mathrm{~m}} \mathrm{Tc}$-sulfurcolloid & 0 & 0 & \\
\hline [19] & 16 & ${ }^{99 \mathrm{~m}} \mathrm{Tc}$-microspheres & 0 & 0 & \\
\hline [42] & 1 & ${ }^{131}$ I-iodocholesterol & 1 & 1 & $\begin{array}{l}\text { Erythematous plaque } \\
\text { and pruritus. }\end{array}$ \\
\hline [43-45] & 12 & ${ }^{201}$ Tl-thallous chloride & 2 & 2 & Radiation ulcer \\
\hline Total & 3016 & & 3 & 3 & \\
\hline
\end{tabular}




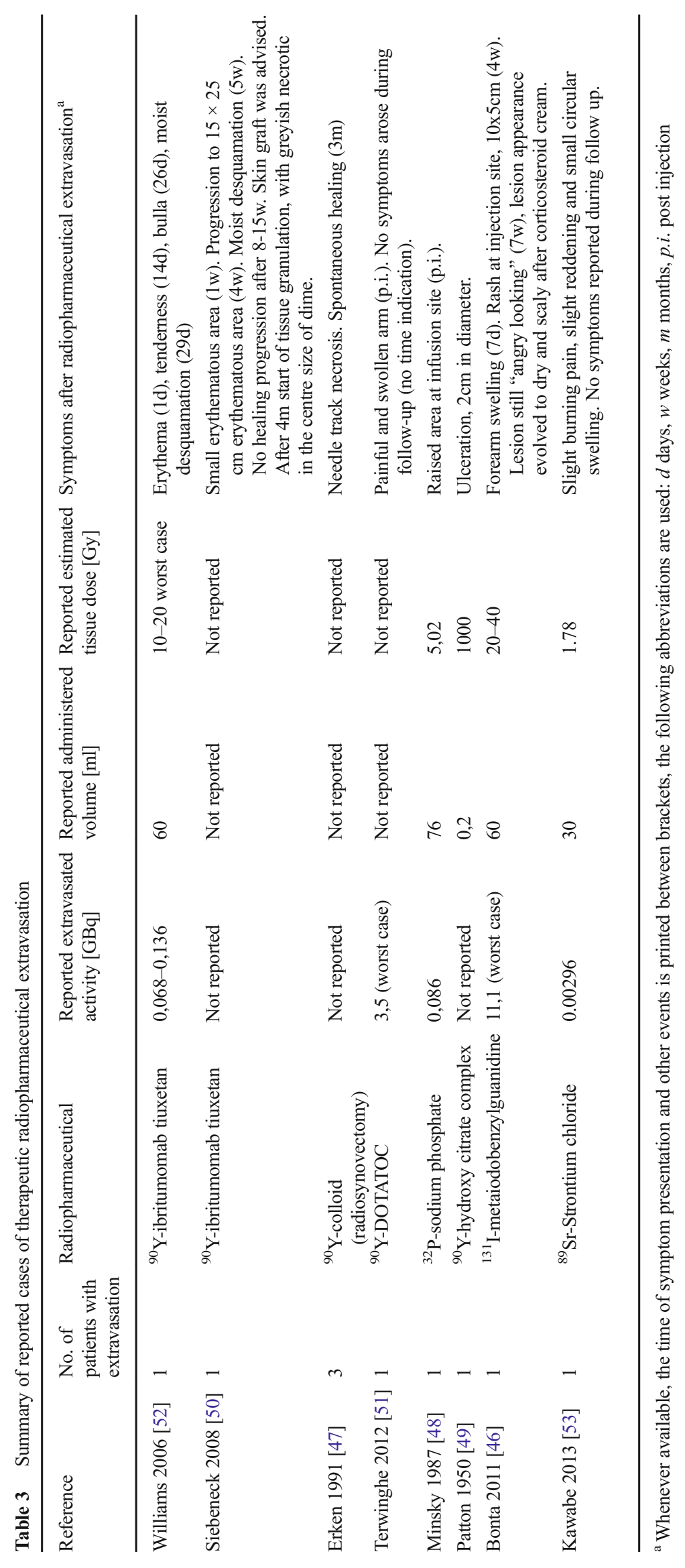




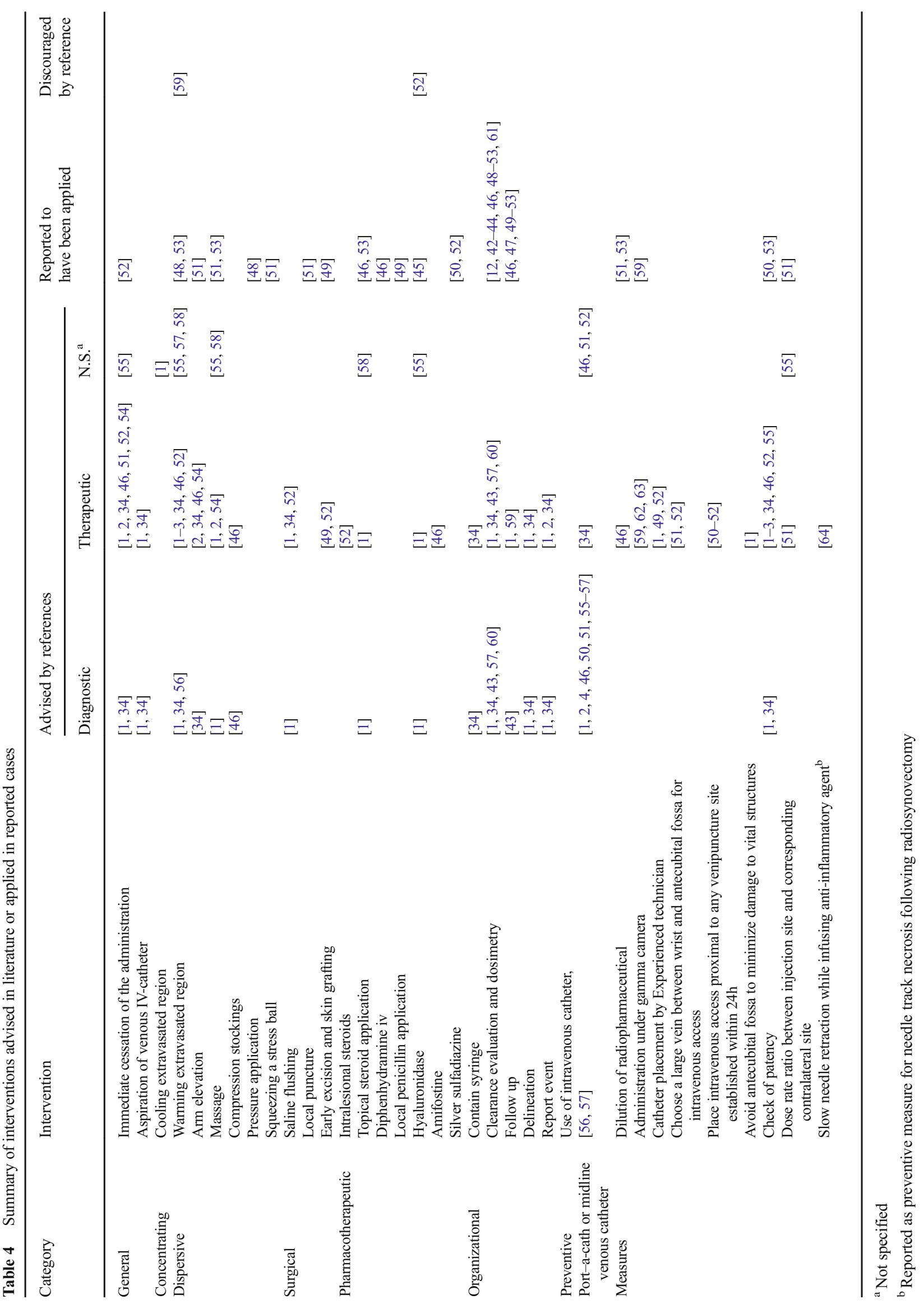


been reported following extravasation of widely and frequently used ${ }^{99 \mathrm{~m}}$ Tc labelled radiopharmaceuticals. Similarly, no cases have been found with any symptoms after extravasation of ${ }^{99} \mathrm{~m}$ Tc, ${ }^{123} \mathrm{I},{ }^{18} \mathrm{~F}$, and ${ }^{68} \mathrm{Ga}$ labelled radiopharmaceuticals. These radiopharmaceuticals together comprise a great majority of radiopharmaceuticals in use on a daily basis in general nuclear medicine practices. Lack of clinical follow-up after diagnostic nuclear medicine scans, but also a conservative attitude towards reporting and publishing of complications may have possibly lead to under-reporting of skin lesions. Nevertheless, given the long history of frequent usage of these agents and even in case of significant under-reporting, we would have expected that at least a few cases had been reported. Therefore, we consider it safe to be conservative in treatment of extravasation of these tracers. Attention should only be focused on early complications of the extravasation that are not attributable to the radioactivity, such as skin necrosis and compartment syndrome $[65,66]$. Other diagnostic radiopharmaceuticals were reported to cause at least mild skin lesions, notably ${ }^{201}$ Th-thallous chloride and ${ }^{131}$ I-iodine-iodocholesterol. Only a few publications report these cases, which are further elucidated by only limited provided data on dosimetric data, follow-up of the patients, etc. [42-44]. Particularly the long period of 2 and 3 years after ${ }^{201}$ Th-thallous chloride raise questions whether the skin lesions were radiation induced. Furthermore, it should be mentioned that ${ }^{131}$ I-iodine-iodocholesterol is used only sporadically nowadays. Nevertheless, in our opinion this warrants at least minimal preventive measures and follow-up after extravasation of these tracers.

Few complications following therapeutic extravasation were reported, yet some causing severe soft tissue damage. Considering the high prevalence of extravasation in diagnostic procedures, the same could be true for therapeutic radiopharmaceuticals. Nevertheless, it is plausible that generally more care is taken in preventing extravasation.

\section{Therapeutic options}

Applied and advised interventions are mostly derived from treatment regimens of extravasation of non-radioactive agents. Only few were applied in reported cases. Dispersive actions can be effective in extravasation non-radiopharmaceutic agents $[65,66]$. It can be debated if all listed dispersive interventions can be applied to radiopharmaceuticals. For instance, DeNardo argues that hyperthermia can ameliorate success of radiotherapy, similarly it might do more harm in case of extravasation [59]. On the other hand, it is plausible that warming up the tissue to promote hyperaemia and lymphatic flow might reduce the time of exposition enough to at least compensate this radiosensitising effect. Terwinghe et al. showed fast tissue wash out of 90Y-DOTATOC after arm elevation, warming the infiltrated area and squeezing a stress ball. This patient had no soft tissue symptoms during follow-up. Moreover they argue that the relatively low molecular weight contributes to faster tissue wash out, in comparison to radiopharmaceuticals with higher molecular weight, particularly in case of 90Y-ibritumomab tiuxetan [51]. Concentrating the radiopharmaceutical by cooling the tissue can be applied in anticipation of surgical interventions. Only two cases report the use of surgical techniques. Local puncture was not considered successful after extravasation of ${ }^{90}$ Y-dotatate [51]. In one report from 1950 the ulceration was excised [49]. Other surgical treatments have not been described or advised in literature. Pharmacotherapeutical interventions have been reported in sporadic case reports. Ulcers were treated with antibiotics and discomfort was treated with topical steroids [46, 49, 50, 52, 53]. Intralesional corticosteroid therapy is advised by Williams, based on results after chemotherapy extravasation, but has not been reported in radiopharmaceutical extravasation [52]. Hyaluronidase use is based on results in extravasation of other agents [1, 55], and applied in one case report of 201Tl-thallous chloride extravasation [45]. Williams et al. discourage any use, because of the experimental status [52]. Amifostine might be effective in radiopharmaceutical extravasation for its proven radioprotective properties in radiotherapy [46]. Despite, it remains unknown how it performs in the high linear energy transfer radiation environment of radiopharmaceutical extravasation, while having considerable side effects.

Clearance evaluation and dosimetry are often advised to be part of extravasation management. Different methods have been used, yielding a large range of tissue doses, due to uncertainties such as retained activity and the volume of the infiltrated tissue, as well as the use of worse case scenarios [44, 46, 48, 49, 52, 53, 60, 61]. Sequential activity measurements with probes or gamma-camera can give useful insight in biological half-life, as well as effectiveness of applied interventions $[42,51,52]$. Furthermore, it might be helpful to also estimate the amount, meaning the volume, of extravasation as one can assume, that larger volumes of radioactive extravasation might cause more pronounced side effects than smaller amounts. However, the volume of an extravasation is hardly measurable, at least in the clinical setting and, consequently, to define. This is not only because of the "real time" setting, but it is even more difficult based on a retrospective literature search and analyses. Furthermore, preventive measures are reported, such as the use of an intravenous catheter (IVcatheter) and adequate check of patency for both diagnostic as well as therapeutic extravasation [1, 2, 4, 46, 50, 51, 55-57].

\section{Limitations}

A substantial number of publications reporting on extravasation, or which were otherwise relevant, were found by screening bibliographies and not in the initial search, despite the sensitive elaborate search strategy. This can be at least partially explained by mismatches in searched keywords and the 
subject of the publication. For instance, a number of publications about pitfalls in image interpretation contained a brief case report of extravasation as an example for false positive lymph node visualisation. These publications were filtered out in our initial search because they did not contain the right keywords in title, abstract or keyword index. Similarly, some patient studies investigating a particular tracer for evaluation of a specific pathology also report extravasation, but were also filtered out because no keywords relevant for our search were matched. Others were brief case reports or "image of the month"-type of publications without an abstract, but contained some relevant information in image captions. Finally, we found several congress abstracts for oral or poster presentations that were not indexed in PubMed or Embase. This is a minor shortcoming in our literature search, although the publications that were found this way only reported minimal information on tracer extravasation. Moreover, it is challenging to avoid such difficulties.

We did not analyse the effect of extravasation on the image quality of diagnostic nuclear medicine scans. It is obvious that image quality might significantly be hampered by at least large extravasation leading to a lower degree of tracer uptake in the target tissue (organ) and to the potential need for a new scan. However, as we, in this review, are focusing on clinical consequences for the patients, we do not address this issue in detail. Furthermore, because of the design of the study, gaining more insights into this topic is not possible within the context of this review.

\section{Future perspectives}

The lack of data on interventions underlines the need for further scientific exploration on this subject. Future research is required to establish definite conclusions for all used radiopharmaceuticals, by retrospective or preferably prospective studies of extravasation cases with detailed clinical description, activity measurements, as well as serial scans to assess dynamic behaviour of the tracer in the time after extravasation. Furthermore, similar studies can be performed to evaluate the different therapies possible after extravasation. Alternatively, detailed case reports can proof to be helpful, especially for less used and probably less common extravasation of therapeutic radiopharmaceuticals. Nevertheless, trials performed in centres that treat large numbers of patients with nuclear medicine therapies are preferable.

\section{Local protocol}

In our clinic, every injection of diagnostic and therapeutic radiopharmaceutical is performed via an IV-catheter, preceded

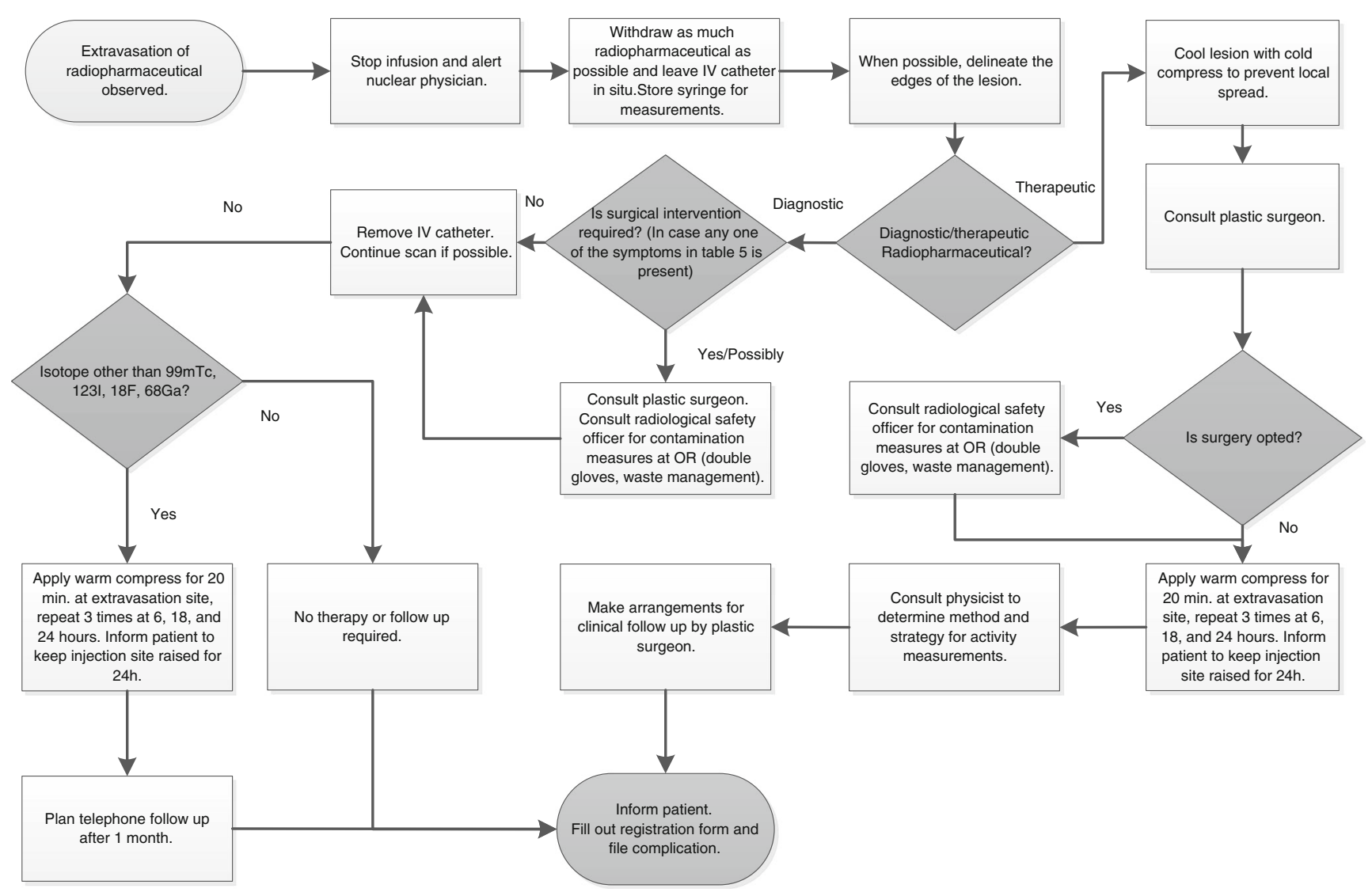

Fig. 1 Flowchart describing the protocol in use in Maastricht University Medical Center for management of radiopharmaceutical extravasation 
by a check of patency that includes flushing the IV-catheter with saline solution, while visually inspecting if swelling occurs and asking the patient if he experiences discomfort during injection. Furthermore, some blood is drawn. When patency is doubtful, a second IV-catheter is inserted and checked for patency. Alternatively, in patients with difficult venous access, this step can be preceded by injecting ${ }^{99 \mathrm{~m}} \mathrm{Tc}$-pertechnetate with the patient's thorax positioned under a gamma camera, to visually confirm systemic spread. For therapeutic administrations, patency is always checked under supervision of the nuclear physician.

Figure 1 shows the protocol that is in use in our hospital for management of radiopharmaceutical extravasation. It is based on the findings of this review. It reflects the negligible probability of adverse events in frequently used ${ }^{99 \mathrm{~m}} \mathrm{Tc},{ }^{123} \mathrm{I},{ }^{18} \mathrm{~F}$ and ${ }^{68} \mathrm{Ga}$ labelled tracers by a conservative approach. A more careful approach has been chosen with relatively harmless preventive measures for diagnostic tracers combined with follow-up, in case of tracers for which adverse events have been reported, notably ${ }^{201} \mathrm{Tl}$-thallous chloride, and for tracers no literature of extravasation was found at all. Although in general radiopharmaceutical administration volume is limited, severe consequences have been reported in non-radiopharmaceutical extravasation, such as tissue necrosis and compartment syndrome [65, 66]. Therefore, in case of any of the symptoms listed in Table 5, the plastic surgeon is consulted. For therapeutic extravasation a plastic surgeon is always consulted to discuss the usefulness of surgery. Until the decision for surgical intervention is made, the lesion is cooled to spare surrounding tissue by preventing spread of the radiopharmaceutical. If no surgical intervention is opted, frequently warming the extravasation area and elevation of the arm are advised to promote spreading of the radiopharmaceutical. Repetitive gamma camera measurements are performed in case of therapeutic extravasation in consultation with the physicist. The patient should always be informed about treatment and potential complications. All cases of extravasation in our hospital are being recorded using a standard form containing detailed information, such as symptoms, the location of extravasation, injected volume and activity, as well as treatment. Furthermore, the incident is documented for the local

Table 5 List of symptoms requiring consultation of a plastic surgeon

Symptom

Swelling $>2.5 \mathrm{~cm}$ in longest axis

Numbness

Blanched, translucent skin

Tight skin, leaking

Discolored, bruised skin

Circulatory or nervous impairment

Moderate-severe pain

Adapted from Amjad et al. [65] complication committee. The strategy applied in this protocol ensures an efficient workflow, by minimizing the effort needed for the most frequently used tracers.

\section{Conclusions}

Extravasation of diagnostic radiopharmaceuticals is common. Often used ${ }^{99 \mathrm{~m}} \mathrm{Tc},{ }^{123} \mathrm{I},{ }^{18} \mathrm{~F}$, and ${ }^{68} \mathrm{Ga}$ labelled tracers do not require specific intervention. Sporadic reports of extravasation of other diagnostic radiopharmaceuticals, however, have described soft tissue lesions. Dispersive intervention and followup is, therefore, advised in other diagnostic radiopharmaceuticals. Extravasation of therapeutic radiopharmaceuticals can lead to severe soft tissue lesions. Although not evidence based, surgical intervention should be considered. Furthermore, dispersive intervention, dosimetry and follow-up is advised. Pharmaceutical intervention has no place yet in the immediate care of radiopharmaceutical extravasation.

Compliance with ethical standards No funding was received for this review. J. van der Pol declares he has no conflict of interest. S. Vöö declares he has no conflict of interest. J. Bucerius declares he has no conflict of interest. F. Mottaghy declares he has no conflict of interest. This article does not contain any studies with human participants or animals performed by any of the authors.

Open Access This article is distributed under the terms of the Creative Commons Attribution 4.0 International License (http:// creativecommons.org/licenses/by/4.0/), which permits unrestricted use, distribution, and reproduction in any medium, provided you give appropriate credit to the original author(s) and the source, provide a link to the Creative Commons license, and indicate if changes were made.

\section{References}

1. Hung JC, Ponto JA, Hammes RJ. Radiopharmaceutical-related pitfalls and artifacts. Semin Nucl Med. 1996;26(4):208-55.

2. Tennvall J, Fischer M, Bischof Delaloye A, Bombardieri E, Bodei L, Giammarile F, et al. EANM procedure guideline for radioimmunotherapy for B-cell lymphoma with 90Y-radiolabelled ibritumomab tiuxetan (Zevalin). Eur J Nucl Med Mol Imaging. 2007;34(4):616-22. doi:10.1007/s00259-007-0372-y.

3. Silberstein EB, Buscombe, J.R., McEwan, A., Taylor, A.T.Jr., .Society of Nuclear Medicine Procedure Guideline for Palliative Treatment of Painful Bone Metastases. Society of Nuclear Medicine Procedure Guidelines Manual. 2003:147-53.

4. Bodei L, Lam M, Chiesa C, Flux G, Brans B, Chiti A, et al. EANM procedure guideline for treatment of refractory metastatic bone pain. Eur J Nucl Med Mol Imaging. 2008;35(10):1934-40. doi: 10.1007/s00259-008-0841-y.

5. Bodei L, Mueller-Brand J, Baum RP, Pavel ME, Horsch D, O'Dorisio MS, et al. The joint IAEA, EANM, and SNMMI practical guidance on peptide receptor radionuclide therapy (PRRNT) in neuroendocrine tumours. Eur J Nucl Med Mol Imaging. 2013;40(5):800-16. doi:10.1007/s00259-012-2330-6.

6. Giammarile F, Chiti A, Lassmann M, Brans B, Flux G. Eanm. EANM procedure guidelines for 131I-meta-iodobenzylguanidine 
(131I-mIBG) therapy. Eur J Nucl Med Mol Imaging. 2008;35(5): 1039-47. doi:10.1007/s00259-008-0715-3.

7. Tennvall J, Brans B. EANM procedure guideline for 32P phosphate treatment of myeloproliferative diseases. Eur J Nucl Med Mol Imaging. 2007;34(8):1324-7. doi:10.1007/s00259-007-0407-4.

8. Alibazoglu H, Megremis D, Ali A, LaMonica G. Injection artifact on FDG PET imaging. Clin Nucl Med. 1998;23(4):264-5. doi:10. 1097/00003072-199804000-00026.

9. Chiang SB, Rebenstock A, Guan L, Burns J, Alavi A, Zhuang H. Potential false-positive FDG PET imaging caused by subcutaneous radiotracer infiltration. Clin Nucl Med. 2003;28(9):786-8. doi:10. 1097/01.rlu.0000082677.96653.22.

10. Hall NZJ. Impact of FDG extravasation on SUV measurements. J Nucl Med. 2006;47 suppl 1:115P.

11. Manohar K, Agrawal K, Bhattacharya A, Mittal BR. New axillary lymph nodal F-18 fluoro-deoxy glucose uptake in an interim positron emission tomography scan - not always a sign of disease progression. Indian J Nucl Med. 2011;26(4):192-3. doi:10.4103/09723919.106703.

12. Oren U, Hiller M, Andersson M. IDACstar: a MCNP application to perform realistic dose estimations from internal or external contamination of radiopharmaceuticals. Radiat Prot Dosim. 2016. doi:10. 1093/rpd/ncw221.

13. Osman MM, Muzaffar R, Altinyay ME, Teymouri C. FDG dose extravasations in PET/CT: frequency and impact on SUV measurements. Front Oncol. 2011;1:41. doi:10.3389/fonc.2011.00041.

14. Pitman AG, Binns DS, Ciavarella F, Hicks RJ. Inadvertent 2-deoxy-2-[18F] fluoro-D-glucose lymphoscintigraphy: a potential pitfall characterized by hybrid PET-CT. Mol Imaging Biol. 2002;4(4): 276-8.

15. Ruibal A. Correction for FDG PET dose extravasations: Monte Carlo validation and quantitative evaluation of patient studies. Med Phys. 2014;41(5):052502. doi:10.1118/1.4870979.

16. Sanchez-Sanchez R, Rodriguez-Fernandez A, Ramirez-Navarro A, Gomez-Rio M, Ramos-Font C, Llamas-Elvira JM. PET/CT: focal lung uptake of 18F-fluorodeoxyglucose on PET but no structural alterations on CT. Rev Esp Med Nucl. 2010;29(3):131-4. doi:10. 1016/j.remn.2010.01.002.

17. Wagner T, Brucher N, Julian A, Hitzel A. A false-positive finding in therapeutic evaluation: hypermetabolic axillary lymph node in a lymphoma patient following FDG extravasation. Nucl Med Rev Cent East Eur. 2011;14(2):109-11.

18. Andrich MP, Chen CC. Bone scan injection artifacts. Clin Nucl Med. 1996;21(3):260-2.

19. Bekier A. The importance of injection technique in radio isotope angiography and cardiography. [German]. Fortschritte auf den Gebiete der Rontgenstrahlen und der Nuklearmedizin. 1975;122(4):341-5.

20. Boxen I. Inadvertent lymphoscintigraphy? Clin Nucl Med. 1985;10(1):25-6.

21. Chatterton BE, Vannitamby M, Cook DJ. Lymph node visualisation: an unusual artefact in the $99 \mathrm{mTc}$-pyrophosphate bone scan. Eur J Nucl Med. 1980;5(2):187-8.

22. Dogan AS, Rezai K. Incidental lymph node visualization on bone scan due to subcutaneous infiltration of Tc-99m MDP. A potential for false positive interpretation. Clin Nucl Med. 1993;18(3):208-9.

23. Giammarile F, Mognetti T, Paycha F. Injection artefact displaying "sock" pattern on bone scan: "glove" sign equivalent resulting from bisphosphonate-(99mTc) injection in foot venous system. Eur J Nucl Med Mol Imaging. 2014;41(8):1644-5. doi:10.1007/ s00259-014-2795-6.

24. Nguyen BD. Technetium-99m MDP extravasation with cutaneous pattern of ulnar innervation. Clin Nucl Med. 2004;29(10):640-1.

25. Ongseng F, Goldfarb CR, Finestone H. Axillary lymph node uptake of technetium-99m-MDP. J Nucl Med. 1995;36(10):1797-9.
26. Peller PJ, Ho VB, Kransdorf MJ. Extraosseous Tc-99m MDP uptake: a pathophysiologic approach. Radiographics. 1993;13(4): 715-34. doi:10.1148/radiographics.13.4.8356264.

27. Penney HF, Styles CB. Fortuitous lymph node visualization after interstitial injection of Tc-99m-MDP. Clin Nucl Med. 1982;7(2): $84-5$.

28. Shih WJ, Collins J, Kiefer V. Visualization in the ipsilateral lymph nodes secondary to extravasation of a bone-imaging agent in the left hand: a case report. J Nucl Med Technol. 2001;29(3):154-5.

29. Shih WJ, Wierzbinski B, Magoun S. Lymph node visualization in the elbow region. J Nucl Med. 1996;37(11):1913.

30. Vieras F. Serendipitous lymph node visualization during bone imaging. Clin Nucl Med. 1986;11(6):434.

31. Wallis JW, Fisher S, Wahl RL. 99Tcm-MDP uptake by lymph nodes following tracer infiltration: clinical and laboratory evaluation. Nucl Med Commun. 1987;8(5):357-63.

32. Spicer KM, Gordon L. Extravasation from venous catheter: a serious complication potentially missed by lung imaging. J Nucl Med. 1983;24(11):1023-6.

33. Stauss J, Treves ST, Connolly LP. Lymphatic Tc-99m DMSA localization after partial-dose extravasation. Clin Nucl Med. 2003;28(7):618-9. doi:10.1097/01.rlu.0000074985.09694.24.

34. Barre E, Nguyen ML, Bruel D, Fournel C, Hosten B, Lao S, et al. Extravasation of radiopharmaceuticals: preventive measures and management recommended by SoFRa (Societe Francaise de Radiopharmacie). Ann Pharm Fr. 2013;71(4):216-24. doi:10. 1016/j.pharma.2013.05.001.

35. Slavin Jr JD, Jung WK, Spencer RP. False-positive renal study with Tc-99m DTPA caused by infiltration of dose. Clin Nucl Med. 1996;21(12):978-80.

36. Ballinger JR, Gulenchyn KY, Reid RH. Radiopharmaceutical factors in the variable quality of [99mTc] HM-PAO images of the brain. J Nucl Med. 1990;31(1):118-22.

37. Biassoni L. Pitfalls and limitations of radionuclide renal imaging in pediatrics. Semin Nucl Med. 2015;45(5):411-27. doi:10.1053/j. semnuclmed.2015.04.001.

38. French BN, Swanson M. Radionuclide-imaging shuntography for the evaluation of shunt patency. Surg Neurol. 1981;16(3):173-82. doi:10.1016/0090-3019\%2881\%2990003-3.

39. Vano-Galvan S, Rodriguez-Rey C, Vano-Galvan E, Jaen P. Technetium and blood extravasation before gammagraphy: a case report. Cases J. 2009;2(1):141. doi:10.1186/1757-1626-2-141.

40. Shih WJ, Han JK, Coupal J, Wierzbinski B, Magoun S, Gross K. Axillary lymph node uptake of Tc-99m MIBI resulting from extravasation should not be misinterpretated as metastasis. Ann Nucl Med. 1999;13(4):269-71.

41. Taillefer R, Robidoux A, Lambert R, Turpin S, Laperriere J. Technetium-99m-sestamibi prone scintimammography to detect primary breast cancer and axillary lymph node involvement. J Nucl Med. 1995;36(10):1758-65.

42. Breen SL, Driedger AA. Radiation injury from interstitial injection of iodine-131-iodocholesterol. J Nucl Med. 1991;32(5):892.

43. Anon. European system for reporting of adverse reactions and drug defects: Third report 1984-1985. European Nuclear Medicine Society News Letter. 1988(9):487-90.

44. Piers DA, Beekhuis H. Local radiation dose from extravasal Tl-201. J Nucl Med. 1987;28:684.

45. Zwart FD. Radiation injury after interstitial injection of iodocholesterol. J Nucl Med. 1992;33(9):1722.

46. Bonta DV, Halkar RK, Alazraki N. Extravasation of a therapeutic dose of 131I-metaiodobenzylguanidine: prevention, dosimetry, and mitigation. J Nucl Med. 2011;52(9):1418-22. doi:10.2967/jnumed. 110.083725 .

47. Erken EHW. Radiocolloids in the management of hemophilic arthropathy in children and adolescents. Clin Orthop Relat Res. 1991;264:129-35. 
48. Minsky BD, Siddon RL, Recht A, Nagel JS. Dosimetry of aqueous 32P after soft-tissue infiltration following attempted intravenous administration. Health Phys. 1987;52(1):87-9.

49. Patton HS, Millar RG. Accidental skin ulcerations from radioisotopes; recognition, prevention and treatment. J Am Med Assoc. 1950;143(6):554-5.

50. Siebeneck BM. Extravasation of yttrium- 90 ibritumomab tiuxetan: a case study. Clin J Oncol Nurs. 2008;12(2):275-8. doi:10.1188/08. cjon.275-278.

51. Terwinghe C, Vanbilloen B, Van Binnebeek S, Baete K, Bergans N, Koole M, et al. Extravasation of 90Y-DOTATOC : case report and discussion of potential effects, remedies and precautions in PRRT. Eur J Nucl Med Mol Imaging. 2012;39:S205. doi:10.1007/s00259012-2221-x.

52. Williams G, Palmer MR, Parker JA, Joyce R. Extravazation of therapeutic yttrium-90-ibritumomab tiuxetan (zevalin): a case report. Cancer Biother Radiopharm. 2006;21(2):101-5. doi:10. 1089/cbr.2006.21.101.

53. Kawabe J, Higashiyama S, Kotani K, Yoshida A, Tsushima H, Yamanaga T, et al. Subcutaneous extravasation of Sr-89: usefulness of bremsstrahlung imaging in confirming $\mathrm{Sr}-89$ extravasation and in the decision making for the choice of treatment strategies for local radiation injuries caused by Sr- 89 extravasation. Asia Ocean J Nucl Med Biol. 2013;1(2):56-9.

54. Hagenbeek A, Lewington V. Report of a European consensus workshop to develop recommendations for the optimal use of (90) Yibritumomab tiuxetan (Zevalin) in lymphoma. Ann Oncol. 2005;16(5):786-92. doi:10.1093/annonc/mdi148.

55. Keeling DH, Maltby P. Maladministrations and misadministrations. Nucl Med Commun. 1994;15(2):63-5.

56. Castronovo Jr FP, McKusick KA, Strauss HW. Dosimetric consequences of radiopharmaceutical infiltrations. Investig Radiol. 1994;29(1):59-64.
57. Hoop B. The infiltrated radiopharmaceutical injection: risk considerations. J Nucl Med. 1991;32(5):890-1.

58. Vallabhajosula S, Killeen RP, Osborne JR. Altered biodistribution of radiopharmaceuticals: role of radiochemical/pharmaceutical purity, physiological, and pharmacologic factors. Semin Nucl Med. 2010;40(4):220-41. doi:10.1053/j.semnuclmed.2010.02.004.

59. Denardo GL. Editorial: "right place, wrong place": extravasation of therapeutic drug for molecular targeted radiotherapy. Cancer Biother Radiopharm. 2006;21(2):85-7. doi:10.1089/cbr.2006.21. 85.

60. Shapiro B, Pillay M, Cox PH. Dosimetric consequences of interstitial extravasation following i.v. administration of a radiopharmaceutical. Eur J Nucl Med. 1987;12(10):522-3.

61. Williams ES. Adverse reactions to radio-pharmaceuticals: a preliminary survey in the United Kingdom. Br J Radiol. 1974;47(553): 54-9. doi:10.1259/0007-1285-47-553-54.

62. Rhymer SM, Parker JA, Palmer MR. Detection of 90Y extravasation by bremsstrahlung imaging for patients undergoing $90 \mathrm{Y}-$ ibritumomab tiuxetan therapy. J Nucl Med Technol. 2010;38(4): 195-8. doi:10.2967/jnmt.110.077354.

63. Wright CL, Monk 3rd JP, Murrey Jr DA, Hall NC. Real-time scintigraphic assessment of intravenous radium-223 administration for quality control. Biomed Res Int. 2015;2015:324708. doi:10.1155/ 2015/324708.

64. Rodriguez-Merchan EC, Goddard NJ. The technique of synoviorthesis. Haemophilia. 2001;7 Suppl 2:11-5.

65. Amjad I, Murphy T, Nylander-Housholder L, Ranft A. A new approach to management of intravenous infiltration in pediatric patients: pathophysiology, classification, and treatment. J Infus Nurs. 2011;34(4):242-9. doi:10.1097/NAN.0b013e31821da1b3.

66. Reynolds PM, MacLaren R, Mueller SW, Fish DN, Kiser TH. Management of extravasation injuries: a focused evaluation of noncytotoxic medications. Pharmacotherapy. 2014;34(6):617-32. doi:10.1002/phar.1396. 